Conference Paper

\title{
Posttraumatic Stress Disorder in Courtroom: Insanity Defence
}

\author{
Vito Zepinic \\ Psych Clinic, London, UK \\ Email address: \\ vito@psychclinic.net
}

\section{To cite this article:}

Vito Zepinic. Posttraumatic Stress Disorder in Courtroom: Insanity Defence. American Journal of Applied Psychology. Vol. 6, No. 2, 2017, pp. 22-30. doi: 10.11648/j.ajap.20170602.12

Received: April 1, 2017; Accepted: April 12, 2017; Published: April 28, 2017

\begin{abstract}
Since the Posttraumatic Stress Disorder (PTSD) has been recognised as an independent mental disorder [1] this disorder became leading disorder present in the courtroom. The definition of the psychological trauma and stressor-related disorders have had many changes in order to clarify diagnostic criterion of the disorder related to the exposure to traumatic or stressful event. However, as psychological distress following exposure to the traumatic event or stressful event is quite variable and, for the past more than three decades, the clinicians tried to establish the most reliable assessment and treatment techniques for PTSD. At the same time, the law faces its own dilemma about this disorder in particular when serious clinical case is charged for the offence. To both the medicine and the law it is clear that many individuals who have been exposed to the traumatic or stressful event exhibit a phenotype in which the most prominent clinical characteristics are anhedonic and dysphoric symptoms, externalizing anger and rage, dissociative symptoms, and relationship changes [2]. Subsequently, PTSD made its way into the courtroom as the outcomes of criminal defences for both violent and non-violent crime.
\end{abstract}

Keywords: Mental Disorders, PTSD, Disorganised Self, Dissociation, Insanity Defence

\section{Introduction}

Even before the PTSD became an officially independent diagnosis, traumatic stress syndrome, such as a traumatic neurosis of war, was successfully offered as a basis for criminal defence. Soon after its introduction in the DSM-III in 1980, the PTSD diagnosis also made its way into the criminal courts as a basis for several types of criminal defences for violent or non-violent offences. Statistically, about two-third of the all mental disorders 'present' in the courtroom belong to the cases that consider PTSD, but the use of the PTSD as a basis for insanity defence appears to be rare. It is more correct to say that PTSD, as an insanity defence, is non-traditional mental disorder for the insanity. In all jurisdictions is required that the accused in case of retain the insanity defence should suffer from some form of the mental disorders, often termed a disease or defect, to claim criminal no-responsibility. Indeed, the majority of insanity defences involve individuals who suffer from severe psychosis or intellectual disability (mental retardation).
In spite that the PTSD is not diagnostically psychosis, it is common that symptoms could be so severe causing the individual's capacity so disordered, such as in case of dissociation, that the insanity defence could be applicable. Although it was known to the medical practitioners, as well as jurists, for the centuries that the severe traumatic experience (s) might induce long-lasting psychopathology, it was not until 1980 publication of DSM-III marked the term PTSD as an independent disorder. Much of the case law concerning PTSD and criminal defendants has centered on the Vietnam veterans (Vietnam stress syndrome and its associated psychiatric problems) who have gone to the prison due to violence or some other crime offences. Since for the first time being introduced in the diagnostic nomenclature, the diagnostic definitions for the PTSD have been modified. The last edition of DSM-5 [2] introduce new conceptualisation of the complex PTSD that differs from the thesis of single disorder diagnostic features.

The essential features of the PTSD are the development of characteristic symptoms following exposure to one or more 
traumatic events. In some individuals exposed to prolonged and repeated trauma, fear based re-experiencing, emotional, and behavioural symptoms are predominant with traumatic memory system, and evidently disordered self-structure. In some other individuals, arousal and reactive-externalising trauma symptoms are prominent, while in others, dissociative symptoms $^{1}$ (derealisation, depersonalisation) are dominant. However, most of those who have been exposed to repeated or prolonged severe trauma exhibit combinations of these symptoms patterns [3].

Severe trauma such as the war combat, being taken as a hostage, brutal or repeated rape, affect all structures of the victim's personality - one's image of the body and sense of self; and one's values and ideals - and leads to a sense that coherence and continuity of the self are systematically broken down [4]. Severe trauma overwhelms the ordinary human adaptation and resistance as it usually involves the threat to life or bodily integrity and confronts the trauma victim with the extremities of the helplessness, hopelessness, and terror, and evokes the response of catastrophe.

The victims of severe trauma may develop a sense of identity diffusion, fragility, and feelings of self-discontinuity with severe disruption in one's psychological equilibrium and interpersonal relationships [5] [6]. In legal proceedings, various PTSD phenomena have been presented in courtroom as basis for criminal defences in violent and criminal behaviour, including dissociative flashbacks, hyperarousal symptoms, survivor guilt, and the sensation-seeking behaviours [7]. However, there has been little empirical research examining the role of specific PTSD symptoms in criminal behaviour.

\section{PTSD and Insanity Defence}

Insanity defence based on PTSD condition may be sometime viewed sceptically because establishing the diagnosis depends on self-reported symptoms, and quite often co-existing impacts such as alcohol or drugs abuse that may make it difficult to define the degree to which mental capacity at the time of an alleged act was due to the disorder or to voluntary consumed intoxication. According to widespread media reports and history of PTSD, the war-related disorder is the most severe condition that may cause substantial personality changes: alterations of ability to modulate emotions, alterations of identity and the sense of self, alterations of ongoing consciousness and memory, alterations in perception of the perpetrator, alterations in relations with others and intimacy, alterations in physical and medical status, and alterations in system of meaning [6] [8]. Persons with severe PTSD may be at risk of arrest for the criminal domestic violence and other crimes [9]. Numerous researches in US

\footnotetext{
1 In DSM-5 [2], depersonalisation is defined as persistent and recurrent experiences of feeling detached from, as if one were outside observer of, one's mental process or body (e.g., feeling as though one were in a dream: feeling a sense of unreality of self or body or of time moving slowly); derealisation is defined as persistent or recurrent experiences of unreality of surroundings (e.g., the world around the individual is experienced as unreal, dreamlike, distant, or distorted).
}

revealed that among those with combat-related PTSD from Vietnam War, $50 \%$ have a history of lifetime arrest after their services. The combat veterans with PTSD are two to three times more likely to be violent towards a female partner than are veterans without PTSD.

The fact that the different jurisdictions employ different approaches to the insanity has important implications for the accused who is diagnosed with PTSD. When the combat-related PTSD individuals psychologically relive the traumatic situation(s), they may be cognitively aware of their actions but unable to control their behaviour as, during the interview and clinical observation, people with PTSD often believe they are in combat and react with violence as in a real combat situation. Hence, such individuals may be eligible for acquittal in a jurisdiction that has retained the violation component of insanity defence [7]. Another key variable is associated with the question whether the PTSD-base insanity defence is likely to be successful if evidence of the dissociated state with evidential burdens at trail (burden of proof) being applied.

The burden of proof can be broken into two components: the burden of production and the burden of persuasion. The burden of production usually lies with the prosecution and must be met to enable the case to go forward. The failure to do so will result in a legal action being summarily dismissed by the court and thus it will not reach the fact finder for verdict. In contrast, the burden of persuasion focuses on who has been the ultimate obligation to convince the fact finder that the facts, as stated, are true and support a given outcome. Thus, the prosecution must prove each and every element of a changed offense beyond a reasonable doubt before a criminal conviction can be obtained.

However, some juridical systems also place on the accused the burden of persuasion to obtain the desired outcome. There is a general presumption of sanity, and thus the initial burden (called the burden of going forward) is on the accused to introduce evidence creating a reasonable doubt of his sanity. As to the burden of convincing the court, some jurisdictions require the accused to prove insanity by a preponderance of the evidence, while others require the prosecution to prove sanity beyond a reasonable doubt. Hence, even if the diagnosis of PTSD is recognised as a valid foundation for the insanity defence under a test of insanity and some evidence exists regarding the requisite linkage of the mental disorder to a cognitive or volitional impairment, the courts vary as to whether the prosecution of the accused bears the burden of persuasion, a difference that can lead to dramatically different outcomes.

As a result of these variations among the judicial systems, the likelihood of PTSD constituting the requisite foundation for an insanity defence differ from the jurisdiction to jurisdiction. Theoretically, one judicial system with a broadly formulated standard of insanity, it should be possible for the accused to use the PTSD finding as a basis for an insanity defence, but not in other judicial system. This, nevertheless, is selective by the law as in medicine the diagnosis of PTSD has unified criteria prescribed in DSM or ICD. This makes 
discrepancy between expert medical testimony and law acceptance of PTSD for an insanity defence. Apparently, the clinical practice and jurisdiction do not go hand-to-hand regarding these issues as PTSD has limited acceptance as a valid foundation in some systems for a defence. Criminal culpability will vary depending on the jurisdiction's applicable insanity test and the nature and severity of the individual's PTSD. Alternatively, in extreme cases, if an individual can establish an absence of control over his actions, the PTSD defendant may be able to employ an automatism defence.

One hurdle that the accused who suffered from PTSD using this condition for insanity defence prerequisite established opinion that the psychotic condition, as a 'real mental disease', is the most applicable in the court. Hence, in some courts this is a threshold requirement under the insanity tests, and the criminal behaviour is excused only if the testimony confirms the existence of psychotic features in PTSD. This requirement for existence of the insanity defence intends to prevent the accused with a relatively minor psychological impairment from employing the defence to avoid being held accountable for the criminal behaviour.

As a 'psychotic disorder' generally refers to the mental conditions that involve a 'gross impairment in reality testing', the majority of the PTSD diagnosis will be ineligible for the insanity defence as not meeting the 'mental disease' threshold requirement [7]. However, vast majority of the clinicians and experts in PTSD (Courtois, Ford, Foa, Herman, Horowitz, McFairlane, van der Kolk, etc.), as well as the court cases, are agreed that an extreme case of the complex trauma syndrome should be considered as the basis for the insanity defence from the criminal responsibility. This opinion has reliable basis because, before the diagnosis of a complex stress syndrome (complex PTSD) can be assigned, there must be the exposure to an extreme traumatic stressor - exposure to combat or other life-threatening situations [3] [17]. Of course, to do so effectively in the court, the disorder would have to render the defendant unable to substantially appreciate the wrongfulness or criminality of his or her actions.

The complex PTSD may result in a gross impairment in reality testing, especially when the disorder leads the individual that he is reliving a traumatic event or otherwise perceives the surrounding environment to be substantially different (and often more threatening) from that which actually exists. The DSM-5 [2] defines dissociation in PTSD as a disruption in the usually integrated functions of consciousness, memory, identity, or perception of the environment and disturbances may be sudden or gradual, transient or chronic. Consequently, the severely traumatised individuals experience delusions or dissociative states which may be so severe to meet threshold requirements for the insanity defence. The mental impairment in 'simple PTSD', such as a motor vehicle accident with no injuries, may be relatively mild and not involve delusions or dissociation as it is evident in the complex trauma syndrome. In addition, although the severity of the PTSD symptoms experienced by a given individual may vary over time, the 'mental disease' requirement will only be met if the PTSD caused a severe psychiatric impairment at the time of the offence.

The relation of PTSD to criminal behaviour was for the first time hypothesised following the Vietnam War, specifically the relations of the dissociative reactions to criminal behaviour when a veteran enters a survival mode brought on by an environment stimulus reminiscent of the combat trauma was postulated. An unconscious defence (not being conscious of one's actions at the time of the offence) involves the survival's reactions to the danger which is deeply unconscious and out of the control [10]. In addition to insanity, PTSD testimony has been introduced to support a claim of the self-defence and diminished capacity ${ }^{2}$.

However, although the diagnosis of PTSD may not be sufficient to produce finding of the accused's insanity or diminished capacity, the court may order the psychiatric treatment instead of the prosecution. The court usually requires evidence that the disorder is severe to reach requirements to support the insanity defence. Establishing a causal connection between PTSD symptoms and the criminal act can be difficult, especially pursuant to the M'Naghten test's requirement. In Rezaq ${ }^{3}$ case, the court stated that: 'The relevance of the evidence pertaining to defendant's PTSD diagnosis turns on whether defendant's case of PTSD is of sufficient severity to constitute an affirmative defence of insanity'. It may be appropriate to consider insanity only in rare circumstances of the severe trauma syndrome when a dissociative flashback led to an unpremeditated criminal act [11].

Nonetheless, even if the accused pursuing the PTSD-based insanity defence can establish the existence of the requisite mental disease at the time of the offence, he also must show that the mental disorder had the required incapacitating effect (i.e., there must be evident connection between the disorder and the criminal act). If the mental disease (PTSD) did not have the 'specified incapacitating effects at the time of the offence', the insanity defence will fail. Some individuals with severe PTSD will indeed have episodes when they lose touch with the reality and during which they commit their criminal act. This is in particular with the war-related trauma which sufficiently qualifies for an insanity defence, diminished capacity, self-defence, unconsciousness and so on, when symptoms affect the accused's mens rea to the extent necessary to reduce culpability.

Frierson [11] reported an active-duty soldier who was found not guilty for a murder due to his insanity as a result of PTSD. He was referred for a criminal responsibility evaluation in a jurisdiction in which the M'Naghten's standard definition of legal insanity was used. The soldier had been arrested for six counts of assault and battery with an intent to kill, discharging a firearm into a dwelling, and possession of a weapon during the violence. While on leave visiting his relatives several states away from his military base, he awoke in the early

\footnotetext{
2 See: People v Matthews, 154 Cal. Rep. 628 [1979]; Ibn-Thomas v United States, 407 A. 2 d 626, D. C. [1979]

3 United States v Rezaq, 918 F. Supp. 463 D. D. C. [1996]
} 
morning and informed the relatives that someone was shooting at him. He grabbed his rifle, drove his truck to another residence a short distance from his relative's house, banged on the front of the residence door demanding entry, and, as nobody opened the door, he began kicking the door. $\mathrm{He}$ then fired four shots into the door jam. Six people, including four children, were inside the residence, and one of them then immediately called the police.

According to the police report, on their arrival they found a male lying on the ground in front of the parked vehicle with a rifle on the ground next to him. The subject began to crawl around the front driver side vehicle and did not respond on the police order to come out with his hands up. As the additional police unit arrived, they took the man into custody and then transported to the detention centre. The alleged victims of the offence did not know the arrested and had no prior contact with him. The offender stated that he did not know the alleged victims and he was amnestic for of the alleged offence.

While questioned in the police station, the arrested offender stated that he is younger in a family of two; he denied illicit drugs used or any alcohol consumption prior to the offence. He has not been married and has, in general, socialised with others with no significant relationship problems. The arrested has no evidence of any criminal history nor prior psychiatric treatment or treatment by primary care provider for his mental health problems before the alleged offence. He had no history of mental illness and had one arrest for driving vehicle intoxicated after he graduated from high school. He had no history of alcohol or illicit drugs abuse, and there was no family history of mental illness. There was no history of any developmental delays, and had reportedly socialised well with other children. He completed high school and reportedly had no history of behavioural problems while schooling. After finishing high school, he has shortly worked in commercial cable installation and then left his job to join the US Army.

As a member of an infantry division, the arrested had been deployed to Iraq on two occasions before the alleged offence. While serving in Iraq he was never injured but witnessed a fatal injury to a fellow soldier in a tank accident during his first one-year deployment. According to information from the Army record, in the second deployment to Iraq, the arrested was involved in door-to-door operation in Fallujah that were designed to find and capture insurgents. During this operation, his unit experienced daily mortar attack by Iraqis.

When arrested, the ex-soldier reported the onset of combat nightmares during his second deployment to Iraq which worsened after he left Iraq. He stated that the nightmares occurred two to four times a month and involved combat situations, but have always been conflicting and involving different locations of the 'combat'. One of his recurrent nightmares involved him being under fire by the enemies and discovering that he did not have his weapon. He described feeling of detachment and estrangement from the others and reported a restricted ability to have loving feelings for others. He also described diminished interest in the previously enjoyable activities. He described hypervigilance and reported several incidents as aftermaths of experiencing an exaggerated startle response. These symptoms have persisted after his second deployment but he did not seek any treatment about his deteriorated mental health condition. Since the alleged offence, he had been treated at his army base for the suffered PTSD and has been prescribed Sertraline and Zolpidem, a psychotropic medication to threat his stress-related and sleep problems.

His military commander revealed that the week before the arrested went on leave, his unit was engaged in training involving intensive breeching training which included going door-to-door to clear potential neighbourhood in the combat zone. As a part of the training, the unit had been trained to open locked doors by disabling the lock with a shot fired into the door jamb. The commander stated that the arrested was a very good soldier and there was no history of disciplinary action except once being involved in a bar fight after deployment.

According to his relative, the arrested had come into the relative's bedroom and stated that someone had been shooting at him and he was 'going to kill somebody'. His relative told him that he will be in trouble if killed anyone, but the arrested responded 'I will not get in trouble for killing these people'. Despite trying to keep him inside, the arrested was able to pull away from his relative who described arrested sneaking to his truck between other vehicles on his hands and knees. According to the police officer, the arrested asked him 'Why are you stopping me from doing my job?'. The police officer reported that the arrested did not appear to be in his right mind - at times he appeared in his right mind and at the other times he did not know where he was and behaved like he was in Iraq.

The above-stated case illustrates that the individuals with PTSD may successfully employ insanity defence if they exhibit the PTSD symptoms of dissociation. If the patient's crime was one of violence and he indeed believed that he was in traumatic event, which was life threatening, then it could reasonably be concluded that he did not know his actions were wrong as he believed that he is defending his life. During such dissociative state, these individuals believe they are in another environment or setting and grossly misconstrue what is occurring. These PTSD sufferers are neither cognizant of the character of their actions nor the need for them, and thus they do not know the nature and quality of the wrongfulness of their actions.

As discussed earlier, under the M'Naghten rules the accused can qualify for the insanity defence if he/she did not know the nature and quality of the act or did not know that the act was wrong. In Clark $^{4}$ case, the court recognised that the individual diagnosed with PTSD experiencing a dissociative state, or some other symptom(s) and rendered the accused incapable of knowing the nature and quality of his or her reaction or of knowing right from wrong, is likely to be extremely important to the defendant's case. Further, it was also recognised that a person driven by delusions or hallucinations, and who has suffered a loss of control and is unable to restrain his or her behaviour as a result, can qualify for the insanity defence despite knowing what he or she was doing, and that such

4 Clark v Arizona, 548 U. S. 735 [2006] 
behaviour was wrong at the time of defence.

It should be noted that severe PTSD is primarily a deregulation of the fear system as the fear is a necessary emotion at times of danger, and is followed by a stress response - such as fighting, freezing, or fleeing. The survival depends on appraisal threats in order to activate initial survival skills [10]. Once the threat or trauma is over, the fear system in PTSD fails to reset to normal condition keeping the sufferer hyperalert, scanning for dangerous cues as if the event happens again. The spectrum of the one's personality pathology caused by severe trauma experience has significant outcomes on the victim's post-trauma emotions, relationship, and behaviour. A close personal encounter with severe violence, threat or death, confronts trauma victims a 'real danger' and evoke the response of inescapable catastrophe. The aftermaths of the trauma may occur in various forms and degrees of the self-dissolution, paranoia, fragmentation, disintegration, and destructiveness.

\section{Inner Conflict Drives}

Vigilance, the mental and physical preparation for the attack is the most disturbing trauma-survivor's behaviour which invades his life profoundly. The severely traumatised individual appears with self-defensive responsiveness and for him there is no place to complete shed vigilance. Exposed to the continuous 'real threat', the trauma survivor remains mobilised for his survival indefinitely without having any comfort. Persistence of the expectation for a danger is an inescapable terror, without the possibility to make any other response than focusing on 'now-moment', as it was during traumatic experience in order to survive and defend himself. During this period of dissociative flashbacks, the traumatised individual is run by inner conflicts drive - the action is out of his control and unconscious.

Deficits in impulse control have been found in individuals who suffered childhood trauma, particularly when they have experienced multiple traumas. Similarly, if other severely traumatised individuals (war-related trauma, brutal rape, severe assault, terrorism, or any other life-threatening experience) 'relive' traumatic event, they may lose control over their actions and act impulsively which will satisfy test in those jurisdictions that recognise it, leading to successful PTSD insanity defence. During a PTSD-linked dissociative state the person may have reacted as he would have responded to the initial traumatic event.

In some severe PTSD cases, there are dissociative-like states, which may last from a few minutes to several days. During the dissociative-like states, the individual behaves as though he were reliving the traumatic event [12]. The dissociative state may be triggered by various stimuli and accompanied by flashbacks, which in turn could trigger attacks on others. In such circumstances the PTSD-linked dissociative state of mind makes person unable to cognitively appreciate the nature or his wrongfulness of the action. Otherwise, only the diagnosis of PTSD with no evidence of dissociative state, is not enough for the insanity defence. In
Simonson ${ }^{5}$ case, the accused tried to impose insanity defence in regards of murdering two of his supervisors at his place of employment. The accused argued that he had acquired PTSD while serving in Vietnam. He was assessed by a psychologist specialised in working with Vietnam veterans. The testimony confirmed that the accused is suffering from PTSD, however he did not commit his violent crime during the PTSD dissociative flashbacks.

The legal implications of using war-related PTSD as a defence became immense since many cases related to the offences have been committed by the Vietnam War veterans. Jordan [12] reported that about 39,000 Vietnam veterans were in state or federal prisons, 37,500 on parole, 250,000 on probation, and 87,000 were awaiting trial. It was estimated that as many as 40 to 50 percent of Vietnam veterans may suffer symptoms in varying degrees which lead the war-related PTSD sufferers to various levels of crime.

Response to the traumatic event (s) vary with the individual involved and is dependent on a range of personal and environmental factors: the intensity of the traumatic event and the resources available to help the person cope with the stress associated to the event. However, the admissibility and relevance of the PTSD symptoms in defence depends how the criminal justice system has addressed the question. Scepticism was heightened by cases in which malingering PTSD was used as a criminal defence and, in particular, when criminal act received a broad media and public attention such as the insanity acquittal of John Hinckley in $1984^{6}$. These trends most likely made the successful use for PTSD as a criminal defence more difficult.

5 State v Simonson, 669 P. 2d 1092 [1983]. See also: State v Felde, 422 So. 2d 370 [1982]; State v Cartagena-Carrasquilo, 70 F. 3d [1995]; Taus v Senkowski, 293 F. Supp. 2d 238 [2003]

6 United States v John W. Hinckley Jr., 525 F. Supp. 1342. D. D. C. [1981]. On 30 March 1981 in Washington DC, John W. Hinckley attempted to assassinate US President Reagan. The President was wounded in the chest from ricocheted bullet, two secret service officers were wounded and Press secretary James Brady was critically wounded. Hinckley became pathologically obsessed with actress Jodie Foster after watching movie Taxi Driver. He stalked the actress slipping poems and massages under Foster's door, and repeatedly called her. Failing to develop any meaningful contact with the actress, Hinckley fantasised about conducting an aircraft hijacking or committing suicide in front of the actress to get her attention. In the morning before his attempt to assassinate US President, he wrote to the actress: 'The reason I'm going ahead with this attempt now is because I cannot wait any longer to impress you'.

As assassination attempt was broadcasted, the US public was outraged and in particular could not accept Hinckley's defence not guilty by reason of insanity. His criminal defence attorney (Vincent J. Fuller, LLD) was to establish that his client did not 'appreciate the wrongfulness' of his conduct. Defence argued that 'appreciate' means not only cognitive awareness, but also includes an emotional understanding of the consequences of his action. The defence with the testimony of three psychiatrists and one psychologist presented Hinckley as a young friendly man who had a terrible sense of hopelessness, and was totally without the requisite mental capacity to appreciate (both cognitively and emotionally) the wrongfulness of his conduct or to conform his conduct to the requirements of the law. He has been diagnosed with narcissistic personality disorder and dysthymia, as well as borderline and passive-aggressive features.

John W. Hinckley Jr. was acquitted by reason of insanity and institutionalised in the St. Elizabeth's psychiatric hospital. On 27 July 2016, a federal judge ruled that Hinckley would be allowed to be released from St. Elizabeth's psychiatric hospital as he was no longer considered a threat to himself or others. 
There is no generally accepted rule in the case law for the admissibility of an expert witness testimony, peer-reviewed publications supporting it, and the general acceptance of it in the relevant field. With respect to the relevance as recognised psychiatric condition it is evident that even before the addition of PTSD in DSM and ICD, traumatic stress was offered for insanity defence. In Houston ${ }^{7}$ case, an army sergeant shot and killed a man he perceived to be reaching for a weapon. At trail, a defence expert testified that the accused had traumatic neurosis ${ }^{8}$ of war and severe alcoholism, and that the shooting took place while he was in the dissociative state. The court found that he had provided substantial evidence in support an insanity defence.

Erikson [13] spoke about 'identity crisis' - a chaotic and profoundly confused mental state. While treating soldiers for 'battle neurosis', he stated that all of them 'did not know any more who they are... there was a distinct loss of ego identity... the sense of sameness and continuity and the belief in one's social role was gone'. Shortly after introduction of PTSD into DSM-III in 1980, PTSD became the basis for insanity defence in particular involving the Vietnam War veterans in violent and criminal behaviour. In Cocuzza ${ }^{9}$ case, a Vietnam veteran who assaulted a police officer was found to be not guilty by reason of insanity. The accused maintained the he believed he was attacking enemy soldiers, and his claim was supported by the testimony of a police officer that the accused was holding a stick as if were a rifle.

In most cases with PTSD, the accused's behaviour was reminiscent of the combat and crime was committed in a dissociative state. In $\operatorname{Tracy}^{10}$ case, a Vietnam veteran was charged with armed robbery, was found not guilty by reason of insanity based on PTSD. The defence issued that he was in a dissociative state during the robbery, which was triggered by stress and by the sight of a funeral parlour, which was a reminder of his traumatic experience in Vietnam. The court found that the accused is not considered criminally responsible if, as a result of mental illness or defect, he lacked capacity either to appreciate the criminality of his conduct or to conform his conduct to the requirements of the law.

Given that most war veterans verdicts are unpublished, it is not possible to determine how PTSD testimony has fared overall as a basis for the insanity defence. However, analysis indicates that the PTSD phenomenon of dissociative state has been successfully presented as a basis for insanity. Under the M'Naghten rules, an accused is not considered criminally responsible if, as a result of mental disease or defect, he lacked the capacity to understand the nature and quality or the wrongfulness of his conduct. The placement of the burden of proof at the clear-and-convincing level on the accused constitutes a significant shift in many jurisdictions. In the past, the accused had been required only to present evidence in

\footnotetext{
7 Houston v State, 602 P. 2d 370 [1979]

8 It was time when in medicine all mental disorders were classified into two groups: neurosis and psychosis.

9 State v Cocuzza, 1484-79 N. J. Super. C [1981]. See also: State v Heads, 385 So. 2d 230, La [1980]; State v Wood, No. 80-7410 [1982]

10 Commonwealth $v$ Tracy, 539 N. E. 2d 1043 [1989]
}

support of insanity, with the prosecution bearing the burden of showing that the standard for insanity was not met.

With the respect to admissibility of the PTSD phenomenon as a qualifying the mental disorders for insanity, in several jurisdictions, the defence was met with the scepticism, particularly after changes in insanity defence standards. It appears that as a matter of law, some courts have been found PTSD to be a sufficiently severe mental disorder that could lead to insanity, but based on the facts of specific cases, it has sometimes been rejected. In cases in which the insanity defence based on PTSD was successful or was found by appellate courts to be viable, the defence theory involved dissociative phenomena to break with reality [14].

Even when the case satisfies the M'Naghten test with clear-and-convincing evidence that a dissociative state was evident at the time of committed offence, the courts rejected it as a valid basis for insanity in some cases. It should be stated that in most severe traumatised individuals the traumatic memories are deeply unconscious and can be revoked by some triggering factor. In such situations, not being conscious of his actions and driven by inner conflicts, the trauma victim is not aggressor by awareness. In fact, the trauma survivor is a defender of himself from reasonably fears of imminent death or great bodily harm that necessities the use of force to save his life, and the amount of force used by the accused is reasonable necessary to avert the danger and not more than exigency demands.

If violent behaviour triggered by some reminder of the trauma event was not with an excessive force, the PTSD sufferer in perfect 'self-defence' was defending his existence from the life-threatening event or enemy. Expert testimony of his awareness of imminent danger has been used to establish the necessary state-of-mind element of the self-defence namely that the accused reasonably feared of imminent death or serious danger for his bodily integrity. Although the imminent danger is unreal and caused subjective feeling, the accused is unconscious of his irrational thoughts and he believes there was an imminent risk that necessitated the use of force, in particular in cases that involve the homicide or attempted homicide of the accused.

The vast majority of the PTSD cases in the courtroom are war-related disorder and less public awareness has focused on civilian PTSD, which results from trauma exposure that is not combat related. However, researchers have found alarmingly high rates of trauma and civilian PTSD in populations whose lives are rooted in continuously stressful and violent context (for example victims of disastrous events such as the Oklahoma City bombing, September 11 attacks, hurricane Katrina, tsunami in Indonesia and Japan, terrorist attacks in Madrid, London, Paris, ...). PTSD symptoms are strongly associated with violent charges and those civilians with a diagnosis of PTSD reported more substantial incarceration records that did those with less extensive trauma histories who did not have the diagnosis [15]. The civilians with experienced traumatic events more likely behave aggressively in situations that remind them of an original trauma. 
In Kelly ${ }^{11}$ case, the accused was charged with the first-degree murder of her husband. She admitted to the killing, but claimed to have acted in self-defence. In support to this claim, the defence sought to introduce the expert witness testimony on buttered-spouse syndrome, given past abuse of the accused at the hands of her husband, including at the time of homicide. By definition, the buttered-spouse syndrome is a psychological construct that describes and explains behavioural pattern typical of buttered spouses.

The appellant court held that the testimony sought by the accused on buttered-spouse syndrome was in fact relevant to the self-defence. The court reasoned that the testimony was relevant to bolster the credibility of the accused that the subjectively feared for her life. However, in Rogers ${ }^{12}$ case, the accused was convicted of the first-degree murder of her boyfriend. At trial, she sought to present expert witness testimony about battered-women syndrome, which includes characterising disorder as a form of PTSD. The trail court excluded the testimony as did not meeting the standards of administration for defence. On appeal, the court disagreed and held the testimony to be relevant and to meet the standards for admission, noting that PTSD is commonly accepted in the mental health community and that the expert testimony on PTSD has been recognised as admissible by the courts.

In Hines ${ }^{13}$ case, the accused was charged with the intentional murder and robbery of her father and was convicted of the lesser included charges of manslaughter and theft. At the trial, she claimed self-defence, contending that she was abused by her father as a child and that on the day of offence he made sexual advances toward her and threatened her. She contended of having fear for her safety and as a result she killed her father with a hammer. To support her defence, the accused sought to admit expert testimony on PTSD, but trial judge had excluded the testimony. On appeal, the court held that the exclusion of the testimony on PTSD was court error, as this testimony would have been relevant to the accused's claim of self-defence.

Self-defence claims based on PTSD have been offered primarily in jurisdiction that use a subjective test of the reasonableness. Detailed review of the case indicates that expert testimony on PTSD relates to the self-defence focused on the PTSD phenomena of a dissociative state, hyperarousal symptoms, increased impulsivity, re-experiencing of the psychological distress when confronted with an abuser or reminders of past traumas, and the overestimation of danger. In the criminal courts, expert witness testimony on PTSD to the insanity defence has also been used to refute the requisite mens rea for certain criminal charges. In Cebian ${ }^{14}$ case, the accused was charged with cocaine-related offences. Her defence was that she lacked the ability to form requisite state of mind for the crime as a result of PTSD related to abuse by her spouse who was a cocaine dealer. Expert witness testimony on her PTSD was presented by the defence and was

11 State v Kelly, 478 A. 2d 364, N. J. [1984]

12 Rogers $v$ State, 616 So. 2d 1098 [1993]

13 State $v$ Hines, 696 A. 2d 780 [1997]

14 United States v Cebian, 774 F. 2d 446 [1985] admitted.

The reported cases in this article, as well as numerous other cases, represent a wide continuum of the legal, social, and psychological problems associated with PTSD in legal proceedings. In the most PTSD court cases, the accused committed offence due to his anger and rage caused by a reminder of the trauma experience or other triggering factors. In such circumstances the PTSD sufferer claims to be amnestic for the alleged offence. After the offence, the accused appears appropriately remorseful and confused when he sees what kind of offence he committed. Most of them will appear of having a dissociative-like state associated with abuse of alcohol or drugs and triggered by something what had reminded of the trauma event(s).

It is also common that anger and rage could be turned inward in an attempt to punish himself [10], or being involved in activities that will inevitable bring the suffered into the courtroom due to his offence. The PTSD sufferer's illegal behaviours closely followed the significant stressors and self-punishment is caused by an individual's broken spirit and will to thrive, making the affective state flat and non-expressive - inert, lifeless, empty, worthless, and vacuous. The psychological trauma consequently impacts all aspects of the self-structure - one's image of the body; the internalised images of others, and one's values and ideals - and leads to a sense that the self-coherence and self's goals are invaded, assaulted, and systematically broken down. The vulnerable self-structure in severe trauma is the 'self-at-worst' state comprised without the safety net or access to the emotional resources. PTSD court cases revealed that the individual's coping strategies are impaired due to the accused's inability to discharge tension and drives of the inner conflicts.

The PTSD legal cases illustrate complexity for both the medicine and the law to foster the imposition of the doctrinal restrictions of the disorder in defence. In many court cases, the PTSD was seen as 'misleading and inaccurate' that continue creates the ignorance and/or uncertainty to impose insanity defence or limited responsibility. Although aftermath of the traumatic event(s) persists long after the event(s) is over, the courts are reluctant to acknowledge the individual's suffering and one of the reasons is underlying concerns that mitigation could open the window for the 'floodgate' applications for insanity defence or limited responsibility. Considering this, it is worthwhile to mention the opinion expressed by the UK Association of Personal Injury Lawyers [16]: 'It would be inequitable for people who have suffered a recognised psychiatric illness to be denied the damages to which they are entitled due to an erroneous policy aiming to prevent a mythical eventuality'.

\section{Discussion}

In summary, we can say that since the PTSD was introduced as an independent disorder in diagnostic manuals either the DSM or ICD, the disorder has been offered as the basis for defence, including insanity, unconsciousness, self-defence, or diminished capacity and as a mitigating circumstance in 
sentencing. The diagnosis received both negative and positive acceptance by the courts with the different standards of admissibility [7]. In assessing the expert testimony, courts have favourably regarded the direct evaluation of the accused by the expert, confirmation of the traumatic exposure via collateral information, and the existence of the clear-and-convincingly documented PTSD. The courts in most judicial systems found criminal defence based on PTSD to be viable and compelling when a clear and direct connection between the accused's PTSD symptoms and the criminal incident was found by the expert. The PTSD phenomena that the courts found to be most relevant to criminal defence include dissociation, hyperarousal symptoms, hypervigilance symptoms, and the overestimation of the 'imminent' danger.

For the past three decades, war-related PTSD became so increasingly present in legal proceedings following offences committed by the sufferers. Most of severely traumatised individuals report heavy drinking, drugs abuse and violent behaviour related with the PTSD having also many episodes of depression associated with irritability, nervousness, and crying spells. In addition, even the danger is over, the PTSD sufferers report that any trigger that reminds them of the traumatic event(s) produce great distress, in particular the combat-related PTSD patients. They would usually report associations that lead to recurrent and vivid recollections of the war events. Some of these recollections could be so vivid that it seemed the trauma-sufferer is back on the battlefield [17]. Dreams and nightmares related to the trauma experience are quite common. They felt detached from family members and a numbing of responsiveness to the external world as evidenced by decreased interest and constricted emotions [5] [12]. War-related PTSD is also characterised by memory impairment, phobic avoidance of situations that aroused traumatic memories, explosive outbursts of anger, and impotence, and these symptoms could continue without improvement for years [8] [18] [19] [20].

Most legislatures define imminent as being on the brink of or about to happen inescapable. This is quite important in the testimony because of hypervigilance of impeding danger and accuracy perceived the seriousness of the situation before 'real danger' impact the PTSD patient. In such situation, the PTSD patient makes a pre-emptive strike before the threat inflicts damage known to the patient from his previous traumatic experience. Although such psychological self-defence is in regards to a trauma experience and perception of danger, it is frequently not a legal defence considering that the victim who became an offender cannot provide to the court real and convincing evidence of existed danger. However, during the brief dissociative state, the 'insanity plea' may be the most appropriate. In other cases of PTSD, the defence of 'unconsciousness' may be raised. Such defence need not presume defence on insanity, but assumes that the accused acted without conscious awareness. Finally, some cases may be approached from the point of view that PTSD symptoms led the accused decreased social, occupational, and other important areas of functioning.

\section{Conclusion}

Our review of the current status of PTSD in courtroom highlights notable advances that have occurred since the DSM-III published [1] along with gaps in a number of points that bear important implication for both the medicine and the law. There has been an increased interest in the relationship between PTSD and violence, in particular combat-related and criminal responsibility determinations, and in factors that mediate their linkage. There is little doubt that the stress of war leaves residual psychopathology among its sufferers [3] [5] [8] [17] [21]. The society at large and the criminal justice systems have recognised, belatedly, that a large number of ex-soldiers are suffering adverse psychological reactions as a result of their experience in the combat or peace mission. Sympathy and sensitivity toward the problems of the combat-related posttraumatic stress disorder has been halting, especially in light of the tightening of legal insanity standards following insanity acquittal of John Hinkley.

Nevertheless, PTSD diagnostic criteria are sufficiently well defined to enable courts to proper understand this disorder and its offered basis for defences, including insanity, self-defence, unconsciousness, and diminished capacity and as a mitigating circumstance in sentencing. In the most cases, the PTSD dissociations have been the basis for successfully presented arguments of self-defence, diminished capacity, and other mens rea defences. The utility of psychometric testing as an aspect of clinical or forensic practices has been studied as a potentially useful adjunctive tool to aid in the diagnosis of severity and complexity of PTSD and its impact on criminal responsibility determination. Accurately diagnosing PTSD is fundamental for the acceptance of expert testimony as reliable by courts and forensic experts should specifically determine whether and how specific PTSD phenomena played a role in the criminal act in question [14].

The reviews contained in this article have some limitations. First, it is limited to US and UK case law, which is likely to be only partially relevant in other countries. However, as it has been suggested in this article, the diagnostic criteria of PTSD in DSM-5 [2] are broadly recognised around the world with no differences in suffered symptoms. Second, and as discussed earlier, because this review is based on published cases, it cannot address trends in PTSD based criminal defences in military trials. Furthermore, even published cases usually contained only short synopsis of the expert testimony, such that the complete examination of the expert's testimony was not possible. This is in particular when a criminal defendant has actually been deployed on combat-related missions and likely experienced traumatic events that involved a serious threat to his life or physical integrity. Careful attention to the evaluation process and obtaining the extensive (if possible) collateral information that is needed to assess criminal responsibility in defendants with PTSD is crucial to reaching accurate and supportive opinions [4] [7] [8] [11].

Conflict of interest: The author declares not having conflict of interest regarding this article. 


\section{References}

[1] American Psychiatric Association (1980): Diagnostic and Statistical Manual of Mental Disorders, $3^{\text {rd }}$ edition, APA, Washington DC.

[2] American Psychiatric Association (2013): Diagnostic and Statistical Manual of Mental Disorders, $5^{\text {th }}$ edition, APA, Arlington.

[3] Zepinic V (2011): Hidden Scars: Understanding and Treating Complex Trauma, Xlibris Publishing, London.

[4] Zepinic V (2016): Disintegration of the Self-structure caused by Severe Trauma, Psychology and Behavioural Science, 5, 83-92.

[5] Herman J (1992): Trauma and Recovery, Basic Books, New York.

[6] Zepinic V (2012): The Self and Complex Trauma, Xlibris Publishing, London.

[7] Zepinic V (2017): Psychopathy: Guilty brain or guilty mind (unpublished manuscript).

[8] Zepinic V (1997): Psychosocial characteristics of war-related posttraumatic stress disorder, Chapter 10 in Ferguson B \& Barnes D (Eds.): Perspectives on Transcultural Mental Health, TCMH, Sydney.

[9] van Winkle EP \& Safer MA (2011): Killing versus witnessing in combat trauma and reports of PTSD symptoms and domestic violence, Journal of Traumatic Stress, 24, 107-110.

[10] Zepinic V (2015): Persistence of 'Survival Skills' as a Risk for Suicide in Severely Traumatised Individuals, International
Journal of Emergency Mental Health and Human Resilience, 2, 552-558.

[11] Frierson RL (2013): Combat-Related Posttraumatic Stress Disorder and Criminal Responsibility Determinations in the Post-Iraq Era: A review and Case Report, Journal of American Academy of Psychiatry and Law, 41, 79-84.

[12] Jordan HW, Howe GL, Gelsomino J, et al. (1986): Post-traumatic Stress Disorder: A Psychiatric Defence, Journal of the National Medical Association, 2, 119-128.

[13] Erikson EH (1968): Identity, Youth \& Crisis, WW Norton, New York

[14] Berger O, Dale E, McNiel E, Binder RL (2012): PTSD as a Criminal Defence: A Review of Case Law, The Journal of the American Academy of Psychiatry and Law, 40, 509-521.

[15] Donley S, Habib L, Jovanovic T, et al. (2012): Civilian PTSD Symptoms and Risk for Involvement in the Criminal Justice System, The Journal of the American Academy of Psychiatry and the Law, 40, 522-529.

[16] UK Association of Personal Injury Lawyers (2007): The Law on Damages: A Response by the Association of the Personal Injury, UKAPIL, London.

[17] van der Kolk BA, McFairlane AC, Weiseath L (1996): Traumatic Stress, The Guilford Press, New York.

[18] Horowitz MJ (2001): Stress Response Syndrome, $4^{\text {th }}$ ed. Jason Aronson Inc. New York.

[19] Courtois AC \& Ford JD (2009): Treating Complex Traumatic Stress Disorder, The Guilford Press, New York.

[20] Foa EB \& Rothbaum OB (1998): Treating the Trauma of Rape, The Guilford Press, New York. 